\title{
DEVELOPMENT OF METAL SUBSTRATE FOR DENOX CATALYSTS AND PARTICULATE TRAP
}

Final Report

Published March 2006

\author{
PREPARED FOR THE UNITED STATES \\ DEPARTMENT OF ENERGY \\ NATIONAL ENERGY TECHNOLOGY LABORATORY
}

Work Performed Under Contract No. DE-FC04-2002-AL67974

All proprietary information has been removed for the purposes of this final report. 


\section{DISCLAIMER}

This report was prepared as an account of work sponsored by an agency of the United States Government. Neither the United States Government nor any agency thereof, nor any of their employees, makes any warranty, express or implied, or assumes any legal liability or responsibility for the accuracy, completeness, or usefulness of any information, apparatus, product, or process disclosed, or represents that its use would not infringe privately owned rights. Reference herein to any specific commercial product, process, or service by trade name, trademark, manufacturer, or otherwise does not necessarily constitute or imply its endorsement, recommendation, or favoring by the United States Government or any agency thereof. The views and opinions of authors expressed herein do not necessarily state or reflect those of the United States Government or any agency thereof. 
Contributing Authors and Program Managers:

Michael J. Pollard, Caterpillar

Craig F. Habeger, Ph.D., Caterpillar

Megan E. Frary, Ph.D., Formerly Caterpillar

Scott A. Haines, Caterpillar

Amy E. Fluharty, Caterpillar

Youssef A. Dakhoul, Caterpillar

Michael W. Carr, Caterpillar

Paul W. Park, Ph.D., Caterpillar

Matthew O. Stefanick, Caterpillar

Herbert DaCosta, Ph.D., Caterpillar

M. Lou Balmer-Millar, Ph.D., Caterpillar

Michael J. Readey, Ph.D., Caterpillar

Philip H. McCluskey, Ph.D., Caterpillar

Gurpreet Singh, US Department of Energy

Aaron Yocum, NETL 


\section{Objective/Scope}

The objective of this project was to develop advanced metallic catalyst substrate materials and designs for use in off-highway applications. The new materials and designs will be used as catalyst substrates and diesel particulate traps. They will increase durability, reduce flow resistance, decrease time to light-off, and reduce cost relative to cordierite substrates.

\section{$\underline{\text { Executive Summary }}$}

Metallic catalyst substrates are used extensively for diesel oxidation catalysts and have the potential to be used in other catalytic systems for diesel engines. Metallic substrates have many advantages over ceramic materials including improved durability and resistance to thermal shock and vibration. However, the cost is generally higher than cordierite. The most common foil material used for metallic substrates is FeCrAlloy, which is expensive and has temperature capabilities beyond what is necessary for diesel applications.

The first task in the project was Identification and Testing of New Materials. In this task, several materials were analyzed to determine if a low cost substitute for FeCrAlloy was available or could be developed. Two materials were identified as having lower cost while showing no decrease in mechanical properties or oxidation resistance at the application temperatures. Also, the ability to fabricate these materials into a finished substrate was not compromised, and the ability to washcoat these materials was satisfactory. Therefore, both candidate materials were recommended for cost savings depending on which would be less expensive in production quantities.

The second task dealt with the use of novel flow designs to improve the converter efficiency while possibly decreasing the size of the converter to reduce cost even more. A non-linear flow path was simulated to determine if there would be an increase in efficiency. From there, small samples were produced for bench testing. Bench tests showed that the use of non-linear channels significantly reduced the light-off temperature for diesel oxidation catalytic converters.

Finally, the third task was to implement these materials and designs into a full-size converter. Hot shake testing of 13" diameter straight channel substrates showed no significant difference in durability between the current material and the two proposed materials. At the time that this program ended, preparations were being made for full-scale emissions testing of the new design converter for comparison to a traditional straight channel with equal catalyst loading. 
Task 1 - Material Identification and Testing

Subtask 1.1 - Evaluate Current Catalyst Performance

Current catalyst performance from metallic substrate converters with current material and current design were archived for future reference.

Subtask 1.2 - Identify Candidate Materials

Several candidate materials were identified which had similar chemistry to FeCrAlloy with significantly lower price. Previous work had shown that chromia forming stainless steels do not have good washcoat adhesion; therefore, other alloys in the Fe-Cr-Al family were investigated. Two materials, which will be designated as materials $\mathrm{B}$ and $\mathrm{C}$ in this report, were selected for further evaluation.

\section{Subtask 1.3 - Oxide Formation Evaluation}

The oxide formation was analyzed for the current and candidate materials. It was believed, based on literature, that the optimum oxide structure for washcoat adhesion is a "rosette" structure of pure alumina. Even though alloy B has a much lower aluminum content than the current material, it was still able to form this structure as shown in Figure 1. However, the parameters for the formation were much less robust with Alloy B likely due to the lower aluminum content, and the rosette structure itself was much finer. Alloy $\mathrm{C}$ has about the same aluminum content as the current material, and it was easily able to form this structure.
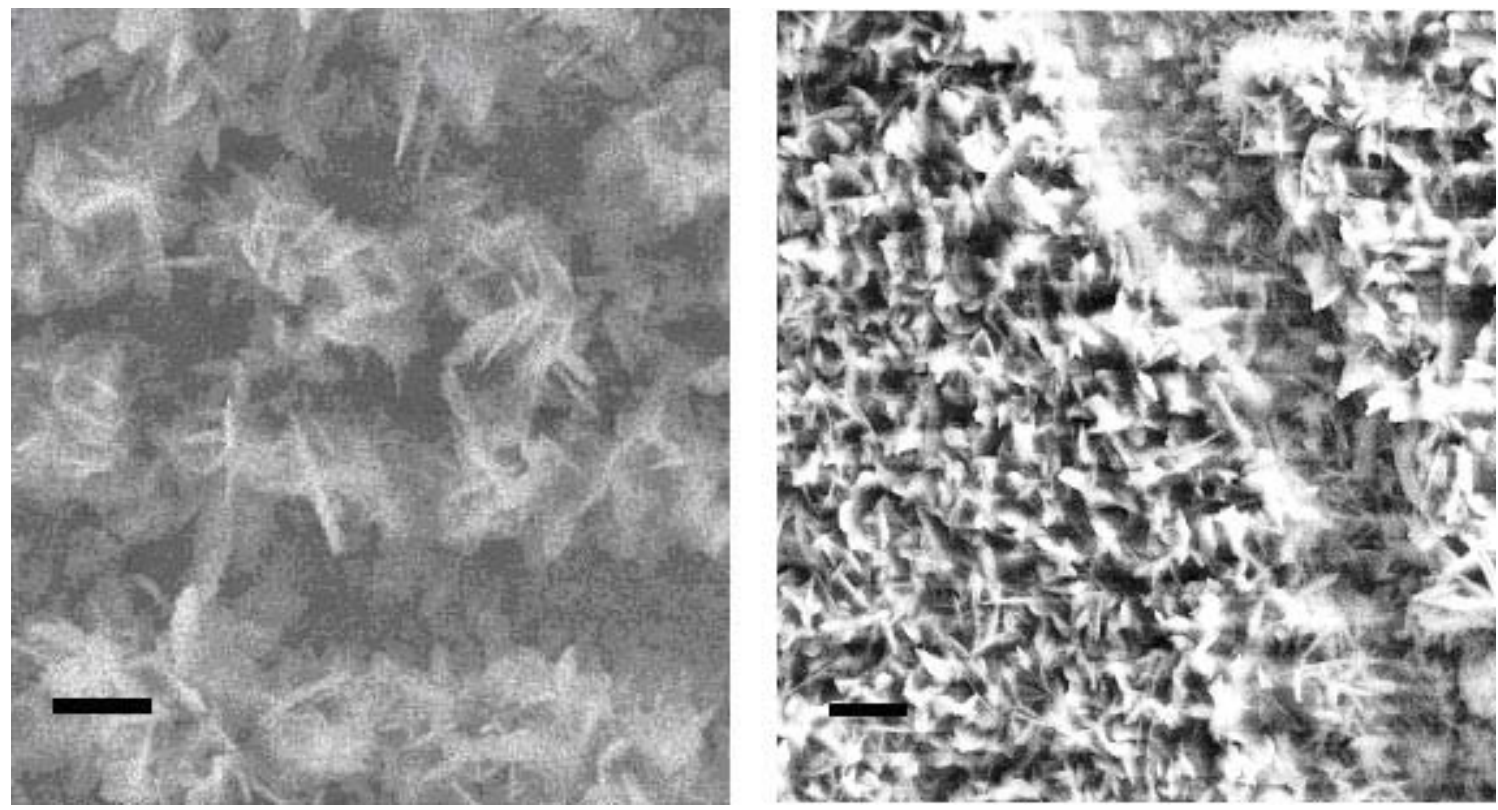

Figure 1. SEM photomicrographs depicting the surface morphology of surface oxides on the current material (left), and material B (right) that were oxidized in air at above $800^{\circ} \mathrm{C}$ for the same time. Note the shape and size of the oxide for each material. The markers are $2 \mu \mathrm{m}$ in length.

However, discussions with suppliers revealed that the current process used a more nodular oxide structure as shown in Figure 2. This was formed at a higher temperature with a much shorter cycle time. The adhesion of this structure was reported as adequate to meet the necessary life of the converter. Both candidate materials and the current material easily formed this structure at the higher temperature. 


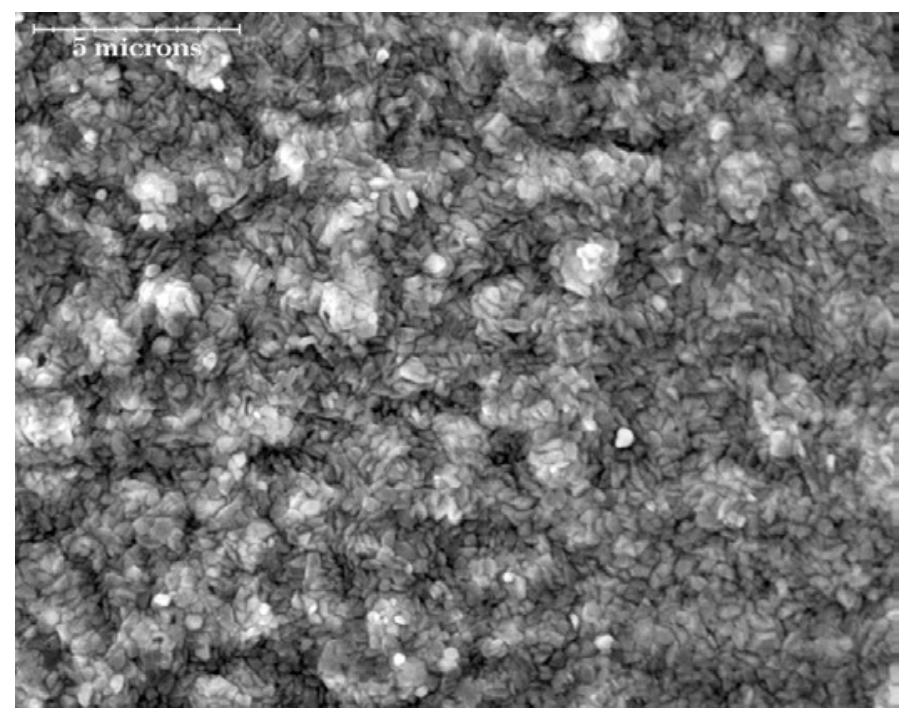

Figure 2. Nodular oxide structure formed at higher temperature for much shorter period of time.

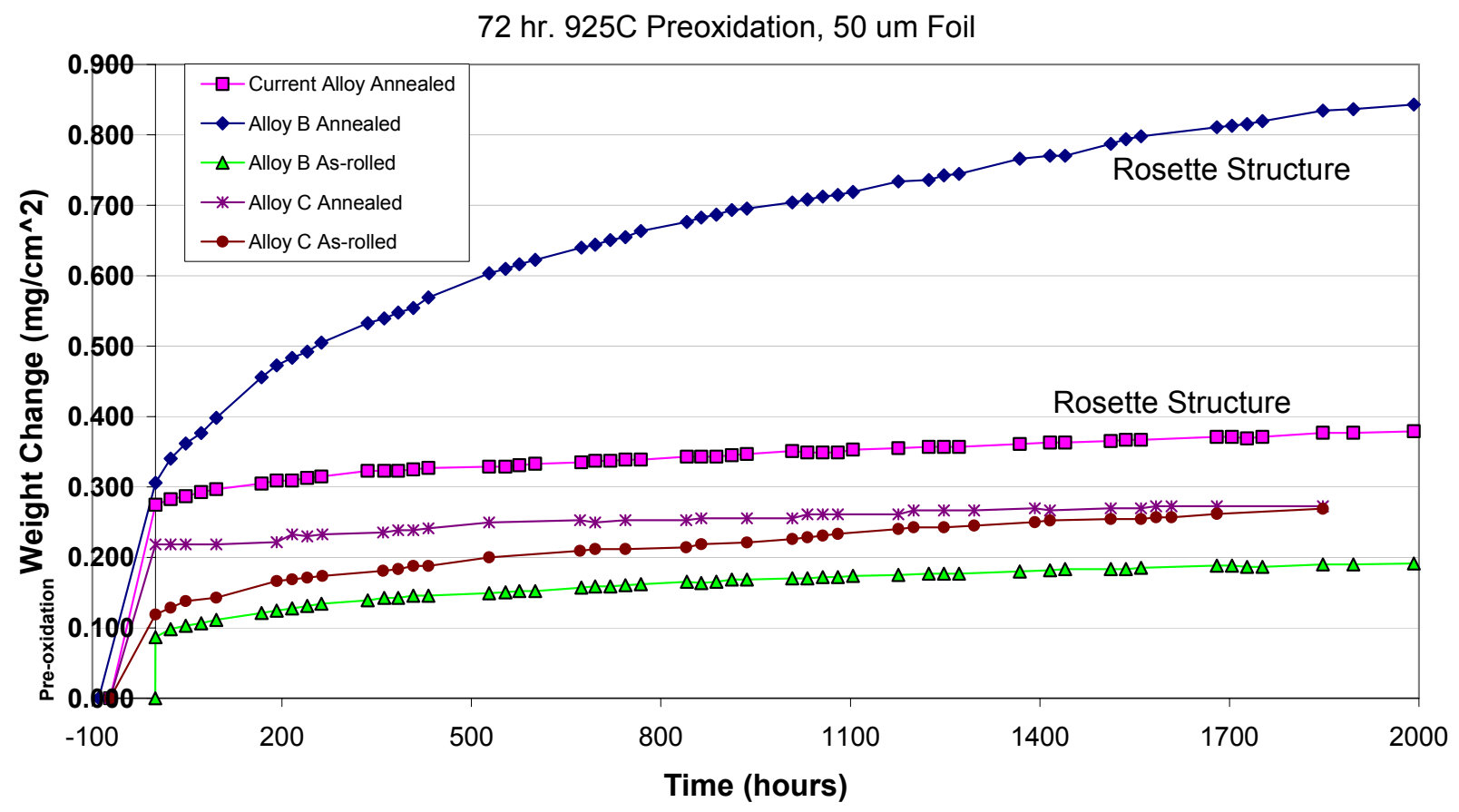

Figure 3. Long-term oxidation resistance of the three different foil materials at $900^{\circ} \mathrm{C}$ in flowing air.

Subtask 1.4 - Oxidation Resistance Analysis

The long-term cyclic oxidation resistance of the two candidate alloys was compared to the current material. Testing was done at $900^{\circ} \mathrm{C}$; this was believed to be an absolute maximum temperature that would be endured in the diesel exhaust environment. Samples of foil were removed from the air-circulating furnace daily and weighed. This process created one thermal 
cycle per day, and testing was continued for 2,000 hours. As can be seen in Figure 3, the oxidation resistance depended as much on the type of oxide that had formed as the alloy itself. It should be noted that even at this temperature, the oxidation is minimal for all materials and conditions tested. Therefore, long-term oxidation resistance of both candidate alloys was adequate.

\section{Task 2 - Alternate Design Testing}

Subtask 2.1 - Model Alternate Design Concepts

Preliminary modeling of new designs with non-linear channels was performed. The analysis was performed by predicting heat transfer coefficient and friction factor as a relative approximation for converter efficiency and backpressure, respectively. The modeling showed increasing heat transfer for non-linear geometry compared to straight channels as shown in Figure 4. However, any increase in heat transfer coefficient was accompanied by an increase in friction factor, which correlates to an increase in backpressure. It should be noted that all modeling was done based on the non-linear design with a flat layer between each corrugated layer. It is possible to produce a substrate with no flat layers between the folded layers when non-linear channels are used; however, due to the complexity of the airflow through such a converter, this was not modeled.

\section{Calculated Colburn Factor " $\mathrm{J} " \quad\left(\right.$ at $R_{e}=1000$ )}

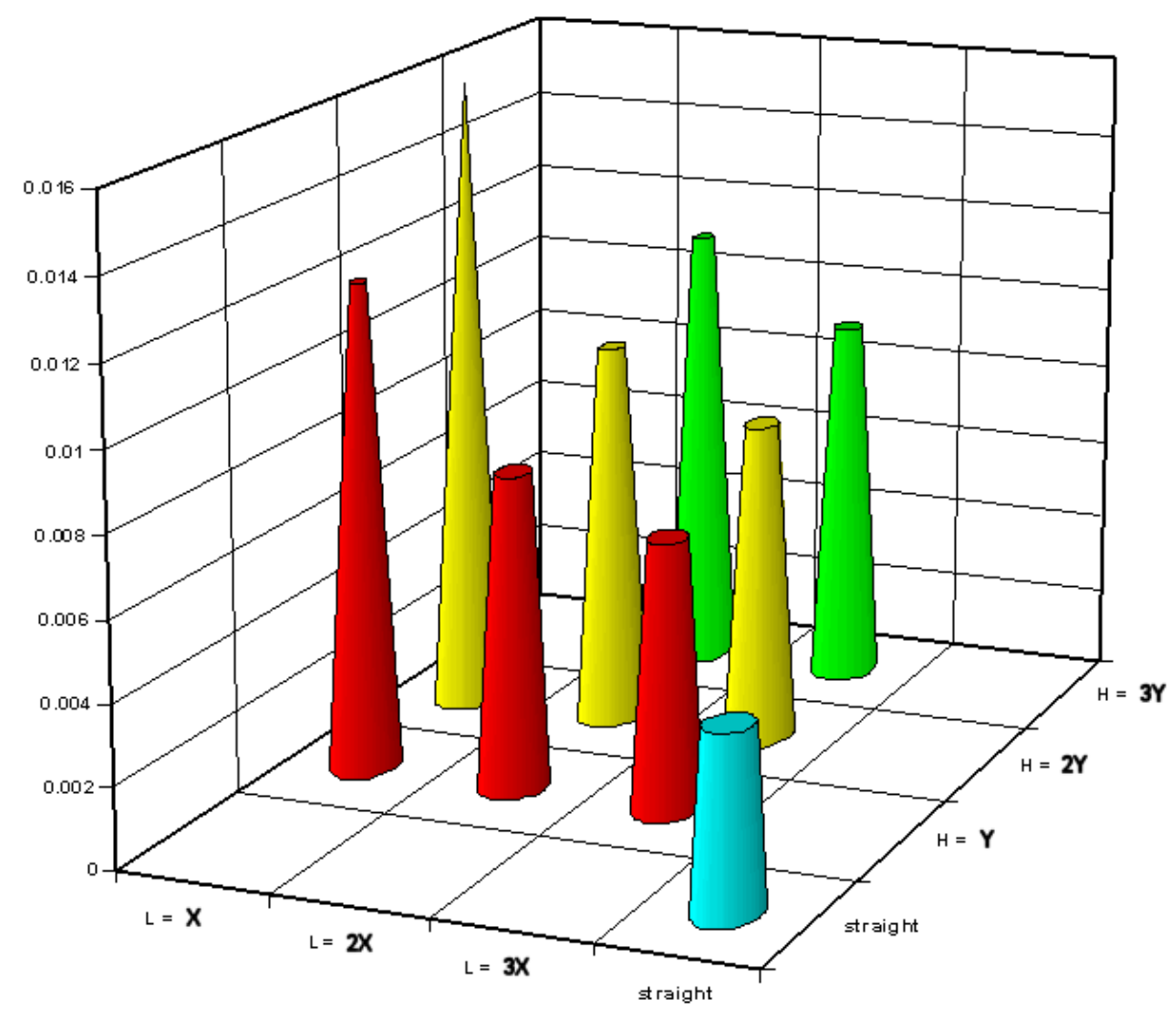

Figure 4. Relative heat transfer coefficient for different foil corrugation geometries.

Subtask 2.2 - Folding Trials 
For the new substrate design concept, it was necessary to determine if the different foil materials in various conditions could be easily corrugated with the new, more complex design. Alloy B annealed, with the lowest aluminum content, was easily formed into the new design at production speeds. Alloy $\mathrm{C}$ annealed was satisfactorily formed into the new design; however, some small crimps and pinholes were evident. Alloy $\mathrm{C}$ has an aluminum content only slightly lower than the current material. When in the as-rolled condition, both Alloys B and C experienced extensive splitting of the foil during corrugation. Therefore, an annealed foil is necessary for the improved design because the foil undergoes tensile deformation during the corrugation.

A much more severe corrugation pattern was also attempted using Alloy B with folding equipment specifically designed for the foil thickness. The foil could be corrugated in this design. This pattern could be used to create an even more tortuous path for the exhaust gas in a converter.

Subtask 2.3 - Small Prototype Analysis

Small samples of the non-linear channel substrates were produced. One substrate was produced with flat plates between corrugated layers. The other was produced with each folded layer shifted by $1 / 2$ period so that the layers contacted at high points rather than nesting. This method allowed the removal of flat foil layers. This would potentially create even more mixing with a lighter design. Bench tests were done to compare the relative catalytic activity of these two nonlinear designs with a straight channel design. The results showed that both of the non-linear channel substrates had lower light-off temperatures than the straight channel samples (See

Figure 5). The non-linear channel sample without any flats consistently had the lowest light-off temperature, while the non-linear channel with flats also performed well. The increase in back pressure in both cases was modest. Modeling was done to optimize the non-linear geometry for the design with flat layers. As expected, the heat transfer (which was used as an approximation for catalytic activity) increases as the wavelength is decreased and the amplitude is increased.

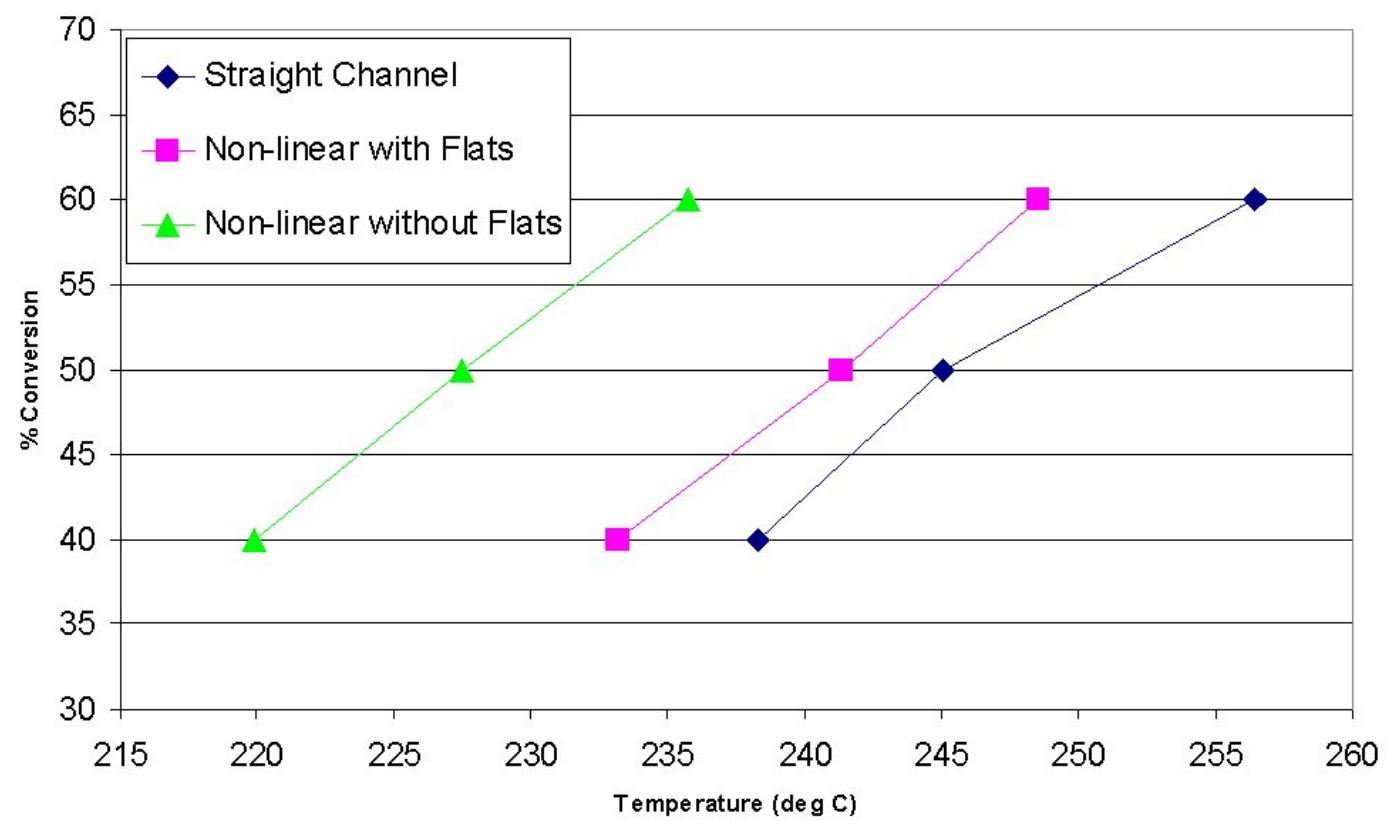


Figure 5. Carbon monoxide oxidation light-off for non-linear channel designs compared to straight channel (Average of three trials).

\section{$\underline{\text { Task } 3 \text { - Implementation }}$}

Subtask 3.1 Full Scale Current Design Prototypes

Hot shake testing of full-size straight channel samples with lower cost materials was completed. Previous hot shake testing had only used vibration at a steady state temperature with no thermal cycling. For this testing, the vibration profile was increased to create an accelerated, yet realistic test. In addition, the substrate was fixtured at $45^{\circ}$ to give the sample side to side loading as well as the up-down vibration (See Figure 6). Finally, a severe thermal cycle was created instead of testing isothermally. This caused all of the samples tested to fail before the $100 \mathrm{hr}$. limit. There is no significant difference in durability between the foil materials tested. Therefore, both new, lower cost materials were deemed to be sufficient for service in diesel engines at much lower cost than standard FeCrAlloy alloys.

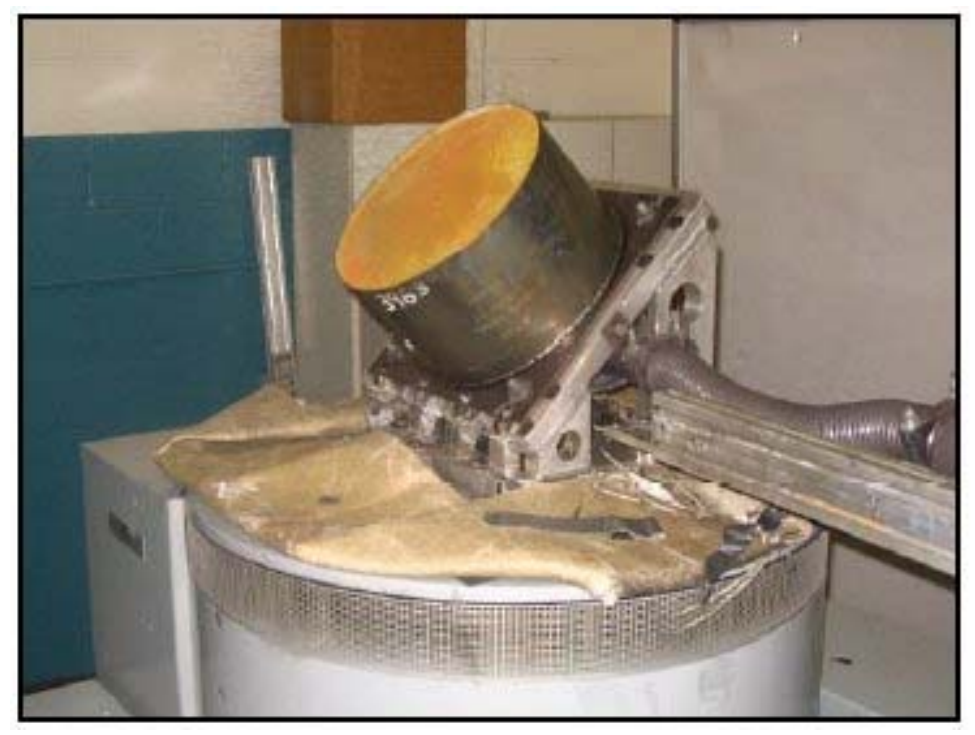

Figure 6. Hot shake test fixture with $45^{\circ}$ mounting to create two-dimensional vibration, which is more representative of the vehicle vibration.

Subtask 3.2 Emissions and Durability Testing of New Material

At the time that this program ended, the converters with new foil materials were awaiting engine emission testing.

Subtask 3.3 Full Scale New Design Prototypes

Since the non-linear channel sample without flats performed so well during bench testing but is not easily modeled, full-scale prototypes were produced with this configuration (See Figure 7). The foil was folded and wound with two separate layers of foil so that the layers would not nest into each other. The substrate was then washcoated. 


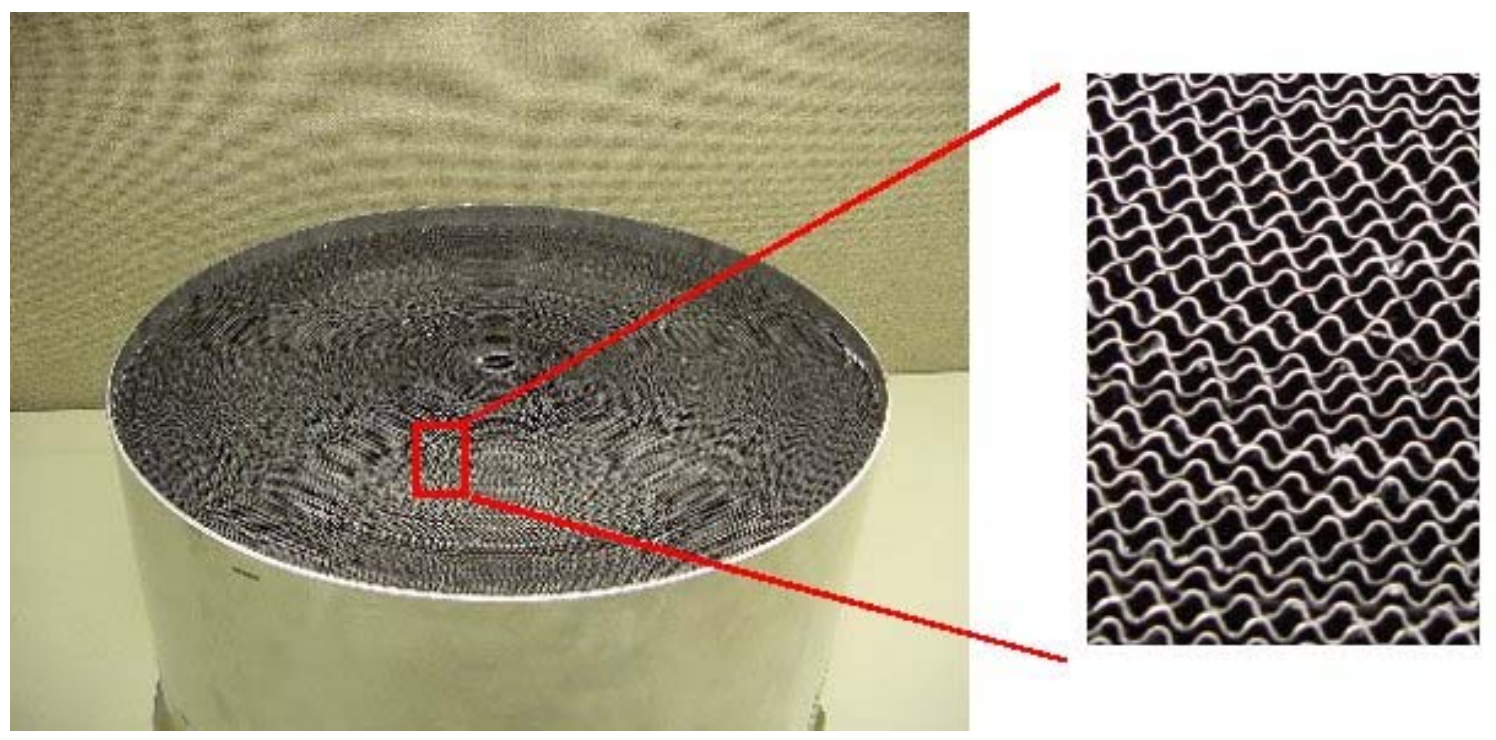

Figure 7. Full-size prototype with non-linear channels and no flat layers.

Subtask 3.4 Emission and Durability Testing of New Design

At the time that this program ended, the first new design converter was awaiting engine emission testing for comparison to a straight channel design. 


\section{$\underline{\text { Written Reports }}$}

2003 Annual Report, CF Habeger, MJ Pollard

2004 Annual Report, MJ Pollard, CF Habeger, PW Park, AE Fluharty

2005 Annual Report, MJ Pollard, CF Habeger, PW Park, H DaCosta, MO Stefanick

Oct to Dec 2002, CF Habeger, MJ Pollard, ME Frary

Jan to Mar 2003, CF Habeger, MJ Pollard, SA Haines

April to June 2003, CF Habeger, MJ Pollard, AE Fluharty, YA Dakhoul, MW Carr

July to September 2003, CF Habeger, MJ Pollard, AE Fluharty, YA Dakhoul, MW Carr

Oct to Dec 2003, CF Habeger, MJ Pollard, AE Fluharty, YA Dakhoul, MW Carr

Jan to Mar 2004, CF Habeger, MJ Pollard, PW Park, AE Fluharty

April to June 2004, CF Habeger, MJ Pollard, PW Park, AE Fluharty

July to September 2004, CF Habeger, MJ Pollard, PW Park, AE Fluharty

October to December 2004, MJ Pollard, CF Habeger, PW Park, MO Stefanick

January to March 2005, MJ Pollard, CF Habeger, PW Park, MO Stefanick, H DaCosta

April to June 2005, MJ Pollard, CF Habeger, PW Park, MO Stefanick, H DaCosta

July to September 2005, MJ Pollard, CF Habeger, PW Park, MO Stefanick, H DaCosta

\section{$\underline{\text { Technical Review Presentations }}$}

Year 1 Technical Review: March 2003, CF Habeger

Year 2 Technical Review: June 2004, MJ Pollard, CF Habeger

Year 3 Technical Review: May 2005, MJ Pollard 